Table SI-1. Classification of model compounds as fast- or slow-reacting chloroform, DCAA and TCAA precursors at pH 8.

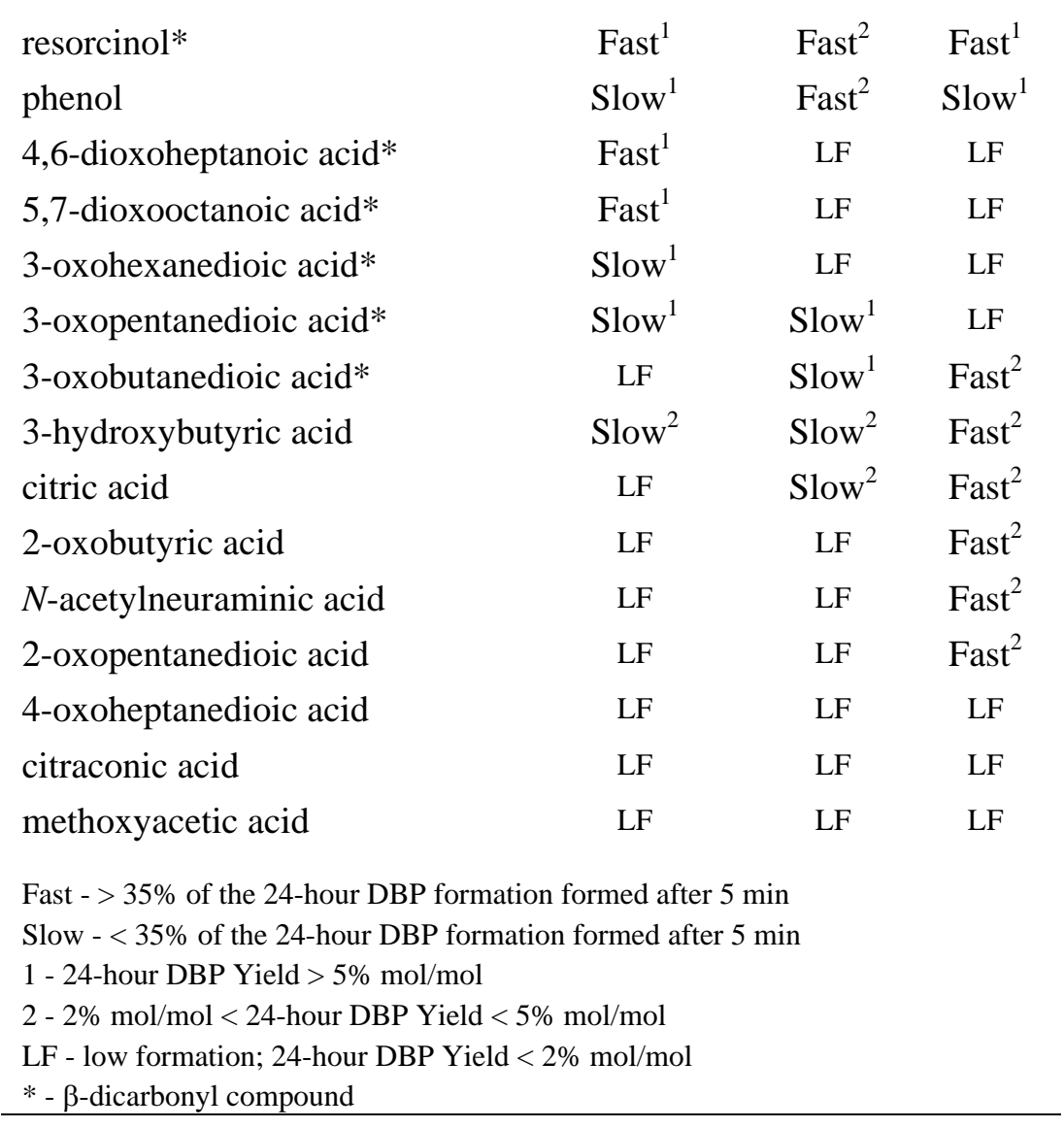

\title{
Chloroform DCAA TCAA
}

resorcinol*

Fast $^{1} \quad$ Fast $^{2} \quad$ Fast $^{1}$

Slow ${ }^{1} \quad$ Fast $^{2} \quad$ Slow $^{1}$

4,6-dioxoheptanoic acid*

acid

Slow

3-oxobutanedioic acid*

citric acid

2-oxobutyric acid

$\mathrm{N}$-acetylneuraminic acid

2-oxopentanedioic acid

4-oxoheptanedioic acid

citraconic acid

LF $\quad$ Slow $^{2} \quad$ Fast $^{2}$

LF $\quad$ LF Fast

Fast - $>35 \%$ of the 24-hour DBP formation formed after 5 min Slow - $<35 \%$ of the 24-hour DBP formation formed after 5 min 1 - 24-hour DBP Yield $>5 \% \mathrm{~mol} / \mathrm{mol}$

2 - 2\% mol $/ \mathrm{mol}<24$-hour DBP Yield $<5 \% \mathrm{~mol} / \mathrm{mol}$

* - $\beta$-dicarbonyl compound 


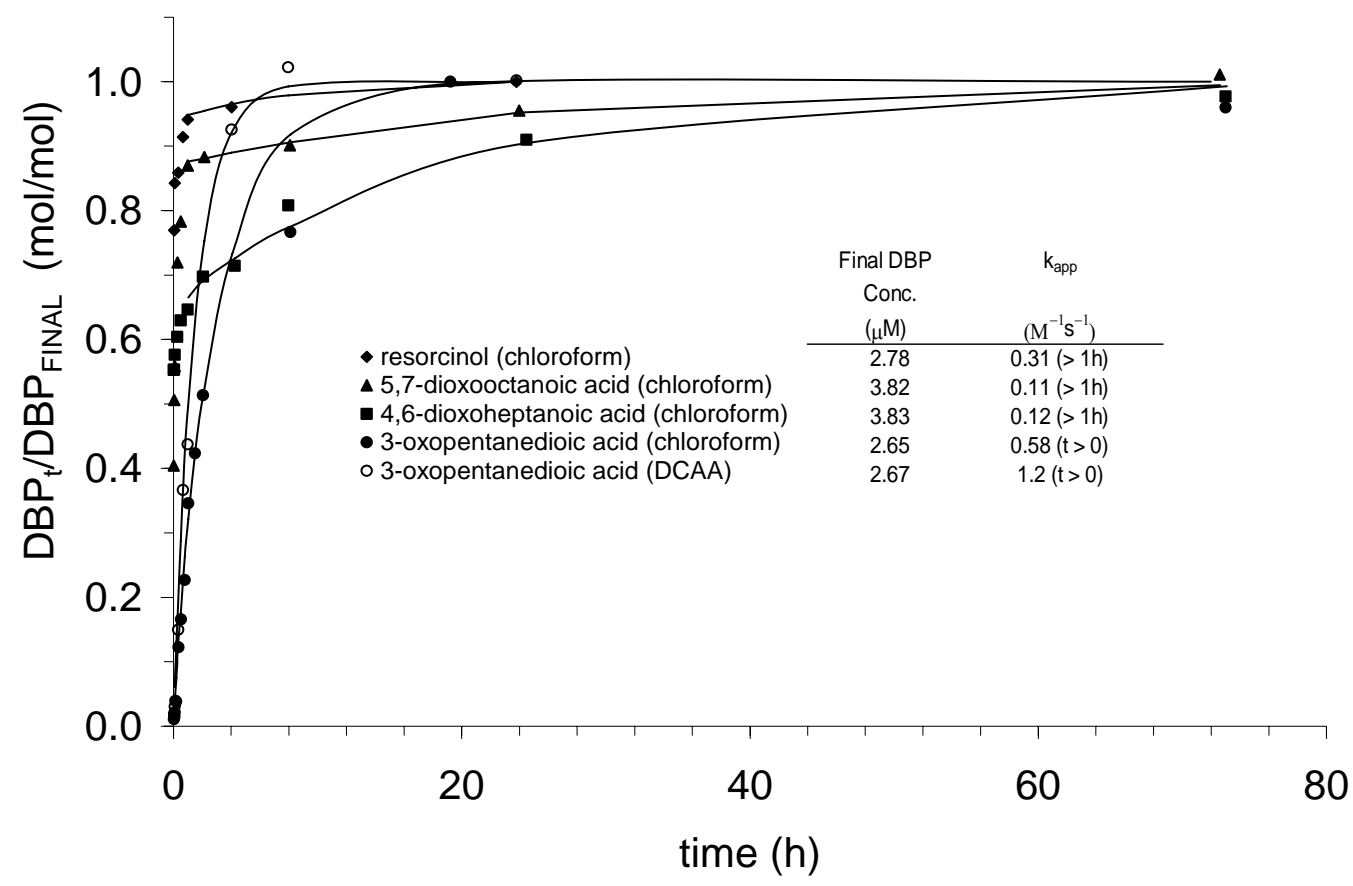

Figure SI-1. Chloroform or DCAA formation kinetics for four model compounds. Solid symbols represent chloroform formation and the open symbol represents DCAA formation at chlorine/compound ratio of $35 \mathrm{M} / \mathrm{M}, 20^{\circ} \mathrm{C}$ and $\mathrm{pH} 8$. 